\title{
Mineralocorticoid Receptor Blockers and Aldosterone to Renin Ratio: A Randomized Controlled Trial and Observational Data
}

\section{Authors}

Stefan Pilz ${ }^{{ }^{*}}$, Christian Trummer ${ }^{1}$, Nicolas Verheyen ${ }^{2}$, Verena Schwetz ${ }^{1}$, Marlene Pandis ${ }^{1}$, Felix Aberer ${ }^{1}$, Martin R. Grübler ${ }^{3}$, Andreas Meinitzer ${ }^{4}$, Antonia Bachmann ${ }^{1}$, Jakob Voelk ${ }^{5}$, Ioana Alesutan ${ }^{5}$, Cristiana Catena ${ }^{6}$, Leonardo A. Sechi' ${ }^{6}$, Winfried März ${ }^{4,7}$, Barbara Obermayer-Pietsch', Andreas Tomaschitz ${ }^{8}$

\section{Affiliations}

1 Department of Internal Medicine, Division of Endocrinology and Diabetology, Medical University of Graz, Graz, Austria

2 Department of Cardiology, Medical University of Graz, Graz, Austria

3 Swiss Cardiovascular Center Bern, Department of Cardiology, Bern University Hospital, University of Bern, Bern, Switzerland

4 Clinical Institute of Medical and Chemical Laboratory Diagnostics, Medical University of Graz, Graz, Austria

5 Department of Internal Medicine and Cardiology, Charité University Medicine, Campus Virchow-Klinikum, Berlin, Germany

6 Hypertension Unit, Internal Medicine, Department of Experimental and Clinical Medical Sciences, University of Udine, Udine, Italy

7 Synlab Academy, Synlab Services GmbH, Mannheim, Germany

8 Bad Gleichenberg Clinic, Bad Gleichenberg, Austria

Key words eplerenone, spironolactone, ARR, RCT, placebo

received 12.01 .2018

accepted 08.03.2018

Bibliography

DOI https://doi.org/10.1055/a-0604-3249

Published online: 3.5.2018

Horm Metab Res 2018; 50: 375-382

(c) Georg Thieme Verlag KG Stuttgart · New York

ISSN 0018-5043

Correspondence

Stefan Pilz MD, PhD

Department of Internal Medicine

Division of Endocrinology and Diabetology

Medical University of Graz

Auenbruggerplatz 15

8036 Graz

Austria

Tel.: + 43/650/9103 667, Fax: +43/316/673 216

stefan.pilz@chello.at

\section{ABSTRACT}

Current guidelines recommend to withdraw mineralocorticoid receptor (MR) blocker treatment for at least 4 weeks when measuring the aldosterone to renin ratio (ARR) as a screening test for primary aldosteronism (PA). We aimed to evaluate the effect of MR blocker treatment on ARR and its components, plasma aldosterone concentration (PAC), and direct renin concentration (DRC). First, we performed a post-hoc analysis of the effect of eplerenone on parathyroid hormone levels in primary hyperparathyroidism (EPATH) study, a randomized controlled trial (RCT) in 110 patients with primary hyperparathyroidism (pHPT). Patients were 1:1 randomly assigned to receive either $25 \mathrm{mg}$ eplerenone once daily (up-titration after 4 weeks to $50 \mathrm{mg} /$ day) or placebo for 8 weeks. Second, we measured the ARR in 4 PA patients from the Graz Endocrine Causes of Hypertension Study (GECOH) before and after MR blocker treatment. Ninety-seven participants completed the EPATH trial, and the mean treatment effect ( $95 \%$ confidence interval) for $\log (e) A R R$ was 0.08 ( -0.32 to 0.48$) \mathrm{ng} / \mathrm{dl} / \mu \mathrm{U} / \mathrm{ml}(\mathrm{p}=0.694)$. The treatment effect was 0.71 (0.47 to $0.96 ; p<0.001) \mathrm{ng} / \mathrm{dl}$ for $\log (e) P A C$ and 0.64 (0.19 to 1.10; $p=0.006) \mu \mathrm{U} / \mathrm{ml}$ for $\log (e)$ DRC, respectively. In the 4 PA patients, the ARR decreased from $11.24 \pm 3.58$ at baseline to $2.70 \pm 1.03(p=0.013) \mathrm{ng} / \mathrm{dl} / \mu \mathrm{U} / \mathrm{ml}$ after MR blocker treatment. In this study with limited sample size, MR blocker treatment did not significantly alter the ARR in PHPT patients but significantly reduced the ARR in PA patients. Diagnostic utility of ARR and its components for PA diagnostics under MR blocker treatment warrants further study.

* These authors contributed equally as first authors to this manuscript 


\section{Introduction}

Primary aldosteronism (PA) is characterized by aldosterone levels that are inappropriately high with regard to major regulators of aldosterone such as angiotensin II, renin or sodium status [1, 2]. Detection of PA is of clinical importance because patients with PA are at higher risk of cardiovascular morbidity and mortality when compared to age-, sex-, and blood pressure (BP)-matched patients with essential hypertension [1-6]. The aldosterone to renin ratio (ARR) is the recommended screening test for PA as it reflects the degree of aldosterone production that is autonomous with regard to its principle trophin renin $[1,2]$.

Measurement and interpretation of the ARR is challenging due to various factors that impact on aldosterone and renin levels [1, 2, 7-11]. A key issue is that several, in particular antihypertensive, drugs interfere with the renin angiotensin aldosterone system $[1,2,8,12,13]$. Therefore, the Endocrine Society Clinical Practice Guideline for the management of PA: case detection, diagnosis, and treatment recommends that "mineralocorticoid receptor (MR) antagonists should be withdrawn at least 4 weeks before ARR testing" [1]. While this is the most important recommendation regarding medication use when measuring the ARR, the data on the impact of MR antagonists (e. g., spironolactone and eplerenone) on the ARR and its components plasma aldosterone concentration (PAC) and direct renin concentration (DRC) is sparse [1, 7, 14-23]. Observational studies and pathophysiological considerations suggest that MR blockers and other potassium sparing diuretics (i.e., amiloride and triamterene) may lead to false negative ARR results as they induce volume contraction and sympathetic nervous stimulation leading to higher DRC and thus lower ARR $[18,19]$. No previous RCT has specifically addressed the effect of eplerenone or spironolactone on the ARR.

Therefore, we aimed to evaluate the effect of MR blocker treatment on ARR and its components, PAC and DRC. First, we performed a post-hoc analysis of the effect of eplerenone on parathyroid hormone levels in primary hyperparathyroidism (EPATH) trial, a randomized controlled trial (RCT) in patients with primary hyperparathyroidism (pHPT) [24, 25]. Second, we investigated PA patients from the Graz Endocrine Causes of Hypertension Study $(\mathrm{GECOH})$ before and after MR blocker treatment $[8,26,27]$.

\section{Subjects and Methods}

\section{EPATH study design}

The EPATH trial is a single-center, randomized, double-blind, parallel-group, placebo controlled trial conducted at the Medical University of Graz, Austria, from December 2012 to February 2015 [24, 25]. In brief, 110 pHPT patients were 1:1 randomly assigned to receive either $25 \mathrm{mg}$ eplerenone once daily (up-titration after 4 weeks to $50 \mathrm{mg} /$ day) or placebo for 8 weeks [24, 25]. The study protocol and the first original publication showing no significant effect of eplerenone on the primary outcome parameter, parathyroid hormone (PTH) levels, have been published elsewhere [24, 25]. The current report of the EPATH trial is a post-hoc investigation on the effect of eplerenone on the non pre-specified outcome parameter ARR, and its components PAC and DRC. The publication of this trial adheres to the CONSORT (Consolidated Standards of Reporting Trials) 2010 statement $[25,28]$. The trial is registered at https://www.isrctn. com/ (ISRCTN33941607) and at https://www.clinicaltrialsregister. eu (EudraCT number: 2011-005683-21). Ethical approval was obtained by the Ethics Committee of the Medical University of Graz, Austria, and all study participants gave written informed consent.

\section{EPATH participants}

Eligible study participants were adults aged 18 years or older with PHPT, a disease characterized by excessive PTH secretion that is inappropriate with regard to the prevailing serum calcium level. pHPT is of interest for the renin angiotensin aldosterone system because MR treatment may impact on PTH levels and vice versa, as MR is expressed in the parathyroid gland and $\mathrm{PTH}$ receptors in the adrenal gland [29]. Further main inclusion criteria were 25(OH)D levels above $50 \mathrm{nmol} / \mathrm{l}(20 \mathrm{ng} / \mathrm{ml})$, estimated glomerular filtration rate (eGFR) (according to the CKD-EPI formula) of more than $50 \mathrm{ml} / \mathrm{min}$, and plasma potassium of $5.0 \mathrm{mmol} / \mathrm{l}$ or less at baseline. Participants were recruited from the outpatient clinics at the Department of Cardiology and the Department of Internal Medicine, Division of Endocrinology and Metabolism, Medical University of Graz, Austria.

\section{EPATH measurements}

Details on baseline and follow-up measurements in the EPATH trial have been published elsewhere [24, 25]. PAC and DRC were determined from EDTA plasma samples that had been stored at $-80{ }^{\circ} \mathrm{C}$ until analysis. PAC and DRC were measured by use of the Immunodiagnostics System (IDS)-iSYS Multi-Discipline Automated System (IDS plc, Boldon, UK) [24]. PAC was determined by the IDS-iSYS aldosterone Immunochemiluminometric assay (ICMA), with an inter-assay coefficient of variation (CV) of 3.83 to $9.71 \%$, and a limit of detection (LoD) of $3.7 \mathrm{ng} / \mathrm{dl}(102.5 \mathrm{pmol} / \mathrm{l})$ [30, 31]. PAC levels below the LoD were set at $3.6 \mathrm{ng} / \mathrm{dl}$. DRC was measured by means of a IDS-iSYS Direct Renin ICMA, with an inter-assay CV of 4.9 to $8.4 \%$ and a LoD of $1.8 \mu \mathrm{U} / \mathrm{ml}$. DRC levels below the LoD were set at $1.7 \mu \mathrm{U} / \mathrm{ml}$.

\section{GECOH study}

The GECOH study is an ongoing diagnostic accuracy study of the ARR in screening for PA. Details on the study protocol and methods have been published previously [8, 26, 27]. In brief, we included adult hypertensive patients who were routinely referred to our outpatient clinic for screening for endocrine hypertension. Drugs that significantly interfere with the renin angiotensin aldosterone system (i.e., spironolactone, canrenoate, eplerenone, amiloride, triamteren, and/or aliskiren) had to be withdrawn at least 4 weeks before study entry. At the first study visit we performed an extensive baseline examination including the measurement of the ARR in the sitting position. The second study visit was performed 2 to 6 weeks later and included a saline infusion test (SIT) in all participants. PA was diagnosed in patients with an ARR of $3.7 \mathrm{ng} / \mathrm{dl} / \mu \mathrm{U} /$ $\mathrm{ml}$ or greater in the sitting position and a PAC of $10 \mathrm{ng} / \mathrm{dl}$ or greater after the SIT. The present investigation is restricted to PA patients with bilateral idiopathic hyperaldosteronism who had available ARR levels at the first study visit and ARR levels under ongoing MR blocker therapy. There were no such data available in patients with aldosterone producing adenomas. PAC was measured by RIA (active aldosterone RIA DSL-8600; Diagnostic Systems Laboratories, Inc., 
Webster, TX, USA) with an intra- and interassay CV of 3.3-4.5 and 5.9-9.8\%, respectively. Plasma DRC concentrations were also determined by RIA (renin immunoradiometric assay RIA 4541; DRG Instruments $\mathrm{GmbH}$, Marburg, Germany) with an intra- and interassay CV of $0.6-4.5$ and $2.7-14.5 \%$, respectively.

\section{Statistical Analysis}

Continuous data following a normal distribution are shown as means with standard deviation and variables with a skewed distribution are shown as medians with interquartile range. Categorical data are presented as percentages. Skewed variables were log(e) transformed before use in parametric statistical analyses.

In the EPATH trial, group comparisons at baseline were performed by unpaired student's t-test, Mann-Whitney U-test, Chi Square test, or Fishers's exact test, as appropriate. Analyses of Covariance (ANCOVA) with adjustments for baseline values were used to test for differences in the outcome variables (i. e., ARR, PAC and DRC) between the eplerenone and the placebo group at the follow-up visit [32].

In the GECOH study, descriptive statistics and paired student's t-test was used to test for within group changes in the outcome variables before (visit 1) and after initiating MR blocker treatment.

A p-value below 0.05 was considered statistically significant. All statistical analyses were performed using SPSS version 23.0 software (SPSS, Chicago, IL, USA).

\section{Results}

Baseline characteristics of the EPATH study cohort are shown in - Table 1. Apart from a significantly lower office diastolic blood pressure in the placebo compared to the eplerenone group, there was no other significant group difference at baseline. Eplerenone treatment was associated with a significant increase in PAC and DRC, but there was no significant effect on the ARR with a mean treatment effect of $\log (\mathrm{e})$ transformed values of 0.08 (95\% confidence interval: -0.32 to 0.48$) \mathrm{ng} / \mathrm{dl} / \mu \mathrm{U} / \mathrm{ml}$ ( $\triangleright$ Table 2 ). In a subgroup analysis of participants without intake of angiotensin converting enzyme-inhibitors, angiotensin II receptor blockers, beta-blockers, thiazide diuretics and nonsteroidal anti-inflammatory drugs ( $n=32$; placebo group $=15$, eplerenone group $=17$ ), there was also no significant treatment effect of eplerenone on the ARR [treatment effect (with $95 \% \mathrm{Cl}$ ) for $\log (\mathrm{e})$ transformed values: 0.07 $(-0.38$ to 0.52$) \mathrm{ng} / \mathrm{dl} / \mu \mathrm{U} / \mathrm{ml} ; \mathrm{p}=0.766]$.

The 4 patients with PA in the GECOH study (mean \pm SD; age: $53.8 \pm 7.6$ years; BMI: $33.1 \pm 9.6 \mathrm{~kg} / \mathrm{m}^{2}$; serum potassium: $3.27 \pm 0.33 \mathrm{mmol} / \mathrm{l} ; 75 \%$ males) all suffered from bilateral adrenal diseases as evidenced by adrenal venous sampling (AVS). Of these, 3 were treated by spironolactone (50 to $100 \mathrm{mg}$ daily) and 1 by eplerenone ( $50 \mathrm{mg}$ daily) for a mean $( \pm$ SD) time of $0.94 \pm 0.79$ years. Notably, two PA patients have withdrawn beta-blockers between baseline and follow-up measurements. Comparing baseline values with values after MR blocker treatment, there was a significant decrease in the ARR ( $\triangleright$ Table 3). This effect was due to an on average approximately 7 fold increase in DRC, whereas PAC increased on average less than 2 -fold ( $\vee$ Table 3 ).

Regarding comparisons of the MR blocker intervention in the EPATH and the GECOH study we observed that no EPATH partici- pant randomized to eplerenone showed a decline of the ARR from baseline to study end that was equal or greater than $-5.41 \mathrm{ng} /$ $\mathrm{dl} / \mu \mathrm{U} / \mathrm{ml}$, which was the lowest decline in the ARR after MR blocker treatment in the GECOH patients. Only 5 (10.5\%) out of 48 EPATH participants randomized to eplerenone had an ARR after treatment of $\geq 1.94 \mathrm{ng} / \mathrm{dl} / \mu \mathrm{U} / \mathrm{ml}$, which was the lowest ARR after MR blocker treatment in the PA patients of the GECOH study. After eplerenone treatment, 21 (43.8\%) out of 48 EPATH participants had DRC $\leq 15.4 \mu \mathrm{U} / \mathrm{ml}$, which is the lowest DRC level that was observed in the 4 PA patients from the GECOH study under ongoing MR blocker treatment.

During the revision of our manuscript, we included one PA patient from the Graz Endocrinology Register study with ARR measurements (by the same assays as in the EPATH trial) before and after starting MR blocker treatment. This PA patient who discontinued urapidil treatment after starting treatment with spironolactone, showed a significant decrease of the ARR from baseline (ARR: $7.59 \mathrm{ng} / \mathrm{dl} / \mu \mathrm{U} / \mathrm{ml}$; PAC: $20.5 \mathrm{ng} / \mathrm{dl}$; DRC: $2.7 \mu \mathrm{U} / \mathrm{ml}$ ) to follow-up (ARR: $1.22 \mathrm{ng} / \mathrm{dl} / \mu \mathrm{U} / \mathrm{ml}$; PAC: $48.1 \mathrm{ng} / \mathrm{dl}$; DRC: $39.3 \mu \mathrm{U} / \mathrm{ml}$ ).

\section{Discussion}

In the RCT in patients with pHPT we have shown that eplerenone treatment increases PAC and DRC without a significant effect on the ARR. In PA patients who were treated with MR blockers, the DRC increased to a much greater extent compared to PAC, leading to a significantly decreased ARR. When comparing the two patient cohorts it was shown that the decline in the ARR after MR blocker treatment was greater in all 4 PA patients than in any EPATH participant treated with eplerenone.

Our findings from the EPATH trial are in line with previous RCTs showing an increase of both, aldosterone and renin levels, in patients treated with MR blockers [16, 17, 22, 23]. In this context, two RCTs, one with spironolactone in 112 CKD stage 2/3 patients and another one with eplerenone in 341 hypertensive patients, both showed significantly increased renin and PAC after MR blocker treatment [16, 22]. In these RCTs, the effect sizes of approximately a doubling to tripling of renin and aldosterone are comparable to our EPATH study, but no previous RCT specifically reported on MR blocker effects on the ARR. The present data from the EPATH trial address this knowledge gap by demonstrating that eplerenone has no significant effect on the ARR in our cohort of patients with PHPT. By contrast, we observed in PA patients from the GECOH study that the ARR was significantly reduced by spironolactone or eplerenone treatment when comparing pre- and post-treatment values. This decrease in the ARR was mainly driven by the strong (approximately 7-fold) increase in DRC in parallel to only a moderate (less than 2-fold) increase in PAC. These data from the GECOH study are in line with some small previous observational studies showing particularly high renin levels in PA patients on MR blocker treatment $[18,20,21]$.

Pathophysiological mechanisms underlying our results are that renin production is increased by MR blocker treatment due to volume contraction and sympathetic nervous system stimulation [18]. In line with this, we observed a significant increase in DRC and PAC after MR blocker treatment in both analyzed studies, which confirms the validity and efficacy of our interventions. The striking dif- 
- Table 1 Baseline characteristics of the EPATH study participants.

\begin{tabular}{|c|c|c|c|c|}
\hline Characteristics & All $(n=97)$ & Eplerenone $(n=48)$ & Placebo $(n=49)$ & p-Value \\
\hline Females (\%) & 78.4 & 79.2 & 77.6 & 0.847 \\
\hline Age (years) & $67.5 \pm 9.5$ & $67.8 \pm 8.6$ & $67.3 \pm 10.4$ & 0.805 \\
\hline Body mass index $\left(\mathrm{kg} / \mathrm{m}^{2}\right)$ & $28.1 \pm 4.8$ & $27.8 \pm 4.0$ & $28.6 \pm 5.4$ & 0.416 \\
\hline Active smoker (\%) & 9.3 & 4.2 & 14.3 & 0.159 \\
\hline Hypertension (\%) & 76.3 & 70.8 & 81.6 & 0.240 \\
\hline Office systolic BP (mmHg) & $144.4 \pm 19.7$ & $147.5 \pm 19.1$ & $141.3 \pm 20.1$ & 0.128 \\
\hline Office diastolic BP (mmHg) & $88.7 \pm 10.9$ & $91.9 \pm 11.6$ & $85.5 \pm 9.1$ & 0.005 \\
\hline NT-proBNP (pg/ml) & $114(62-196)$ & $132(59-221)$ & $104(62-185)$ & 0.493 \\
\hline $\mathrm{DRC}(\mu \mathrm{U} / \mathrm{ml})$ & $9.9(4.7-31.2)$ & $9.1(3.8-27.1)$ & $11.7(5.6-33.8)$ & 0.220 \\
\hline PAC (ng/dl) & $3.6(3.6-6.3)$ & $3.6(3.6-6.1)$ & $3.6(3.6-7.3)$ & 0.436 \\
\hline ARR (ng/dl/ $/ \mu \mathrm{U} / \mathrm{ml})$ & $0.47(0.15-1.01)$ & $0.52(0.18-1.08)$ & $0.44(0.13-0.90)$ & 0.323 \\
\hline eGFR $\left(\mathrm{ml} / \mathrm{min} / 1.73 \mathrm{~m}^{2}\right)$ & $77.6(69.2-88.5)$ & $77.3 \pm 13.8$ & $79.3 \pm 15.0$ & 0.495 \\
\hline Diabetes mellitus (\%) & 8.2 & 4.2 & 12.2 & 0.268 \\
\hline HbA1c (mmol/mol) & $37(35-40)$ & $37(35-39)$ & $38(35-41)$ & 0.150 \\
\hline HDL-cholesterol (mg/dl) & $65(55-78)$ & $69 \pm 23$ & $64 \pm 17$ & 0.269 \\
\hline LDL-cholesterol (mg/dl) & $107(80-138)$ & $115 \pm 41$ & $104 \pm 35$ & 0.186 \\
\hline CRP $(\mathrm{mg} / \mathrm{l})$ & $1.5(0.6-2.7)$ & $1.2(0.6-2.2)$ & $1.6(0.8-3.2)$ & 0.080 \\
\hline $25(\mathrm{OH}) \mathrm{D}(\mathrm{ng} / \mathrm{ml})$ & $34.2 \pm 10.8$ & $33.4 \pm 8.5$ & $35.0 \pm 40.9$ & 0.462 \\
\hline PTH (pg/ml) & $102(82-127)$ & $96(83-119)$ & $108(83-132)$ & 0.241 \\
\hline Plasma total calcium $(\mathrm{mmol} / \mathrm{l})^{*}$ & $2.62 \pm 0.14$ & $2.60 \pm 0.13$ & $2.64 \pm 0.14$ & 0.112 \\
\hline Plasma potassium (mmol/l) & $4.1 \pm 0.3$ & $4.0 \pm 0.3$ & $4.1 \pm 0.3$ & 0.458 \\
\hline Spot urine: sodium to potassium ratio\# & $1.73(1.20-2.28)$ & $1.75(1.10-2.36)$ & $1.68(1.22-2.26)$ & 0.907 \\
\hline NSAID (\%) & 10.3 & 10.4 & 10.2 & 0.973 \\
\hline ACE-inhibitor (\%) & 19.6 & 20.8 & 18.4 & 0.760 \\
\hline AT II blocker (\%) & 26.8 & 22.9 & 30.6 & 0.392 \\
\hline Thiazide diuretic (\%) & 30.9 & 31.3 & 30.6 & 0.946 \\
\hline Loop diuretic (\%) & 3.1 & 4.2 & 2.0 & 0.617 \\
\hline Beta blocker (\%) & 43.3 & 43.8 & 42.9 & 0.929 \\
\hline Calcium channel blocker (\%) & 24.7 & 20.8 & 28.6 & 0.377 \\
\hline \multicolumn{5}{|c|}{$\begin{array}{l}\text { Date are presented as means with standard deviation, medians with interquartile range or as percentages. Comparisons between the eplerenone and } \\
\text { placebo group were calculated with Student's t-test, Mann-Whitney U-test, Chi Square test, or Fisher's exact test, as appropriate. }{ }^{*} \text { Albumin } \\
\text { adjusted plasma calcium values; \# In mmol/I divided by mmol/l; BP: Blood Pressure; NT-proBNP: N-Terminal pro-B-type natriuretic peptide; DRC: } \\
\text { Direct Renin Concentration; PAC: Plasma Aldosterone Concentration; ARR: Aldosterone to Renin Ratio; eGFR estimated: Glomerular Filtration Rate; } \\
\text { HbA1c: Glycosylated hemoglobin A1c; HDL-cholesterol: High-density lipoprotein-cholesterol; LDL: Low-density lipoprotein-cholesterol; CRP. } \\
\text { C-reactive protein; 25(OH)D: } 25 \text {-Hydroxyvitamin D; PTH: Parathyroid Hormone; NSAID: Nonsteroidal anti-inflammatory drug; ACE-inhibitor: } \\
\text { Angiotensin Converting Enzyme-inhibitor; AT II blocker: Angiotensin II receptor blocker. }\end{array}$} \\
\hline
\end{tabular}

ference with regard to no change of the ARR in the EPATH study but a significant decrease in ARR in the GECOH study was mainly due to the extraordinary strong renin increase after MR blocker treatment in PA patients. This may hypothetically be due to the fact that in PA, the degree of renin suppression is mainly caused by absolute aldosterone excess whereas in patients without PA other factors that are likewise less responsible to MR blocker treatment may also play an important role in renin regulation. Therefore, when blocking aldosterone effects by eplerenone or spironolactone, the renin levels are significantly more affected in PA when compared to patients without PA.

Our findings have clinical implications, as they may suggest that absolute levels and changes of PAC and DRC as well as of the ARR in response to MR blocker treatment may be of some diagnostic value. Importantly, our results of the 4 PA patients (see $>$ Table 3 ) provide sound scientific evidence for the recommendation of the Endocrine Society Clinical Practice Guideline for the management of primary aldosteronism that when the ARR is determined under ongoing MR blocker treatment, a normal ARR along with a sup- 
- Table 2 Outcome variables at baseline and follow-up, and treatment effects of eplerenone in EPATH study participants.

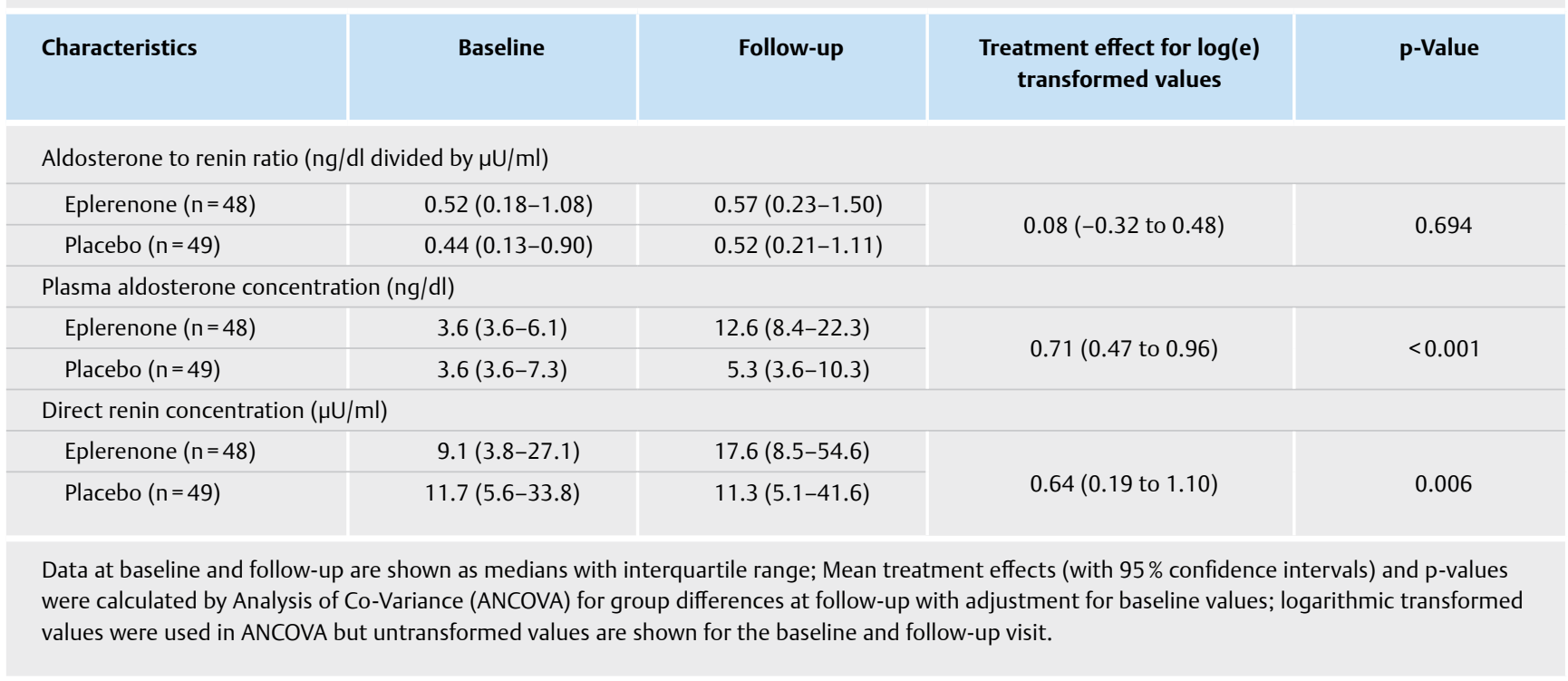

pressed renin, may be diagnostic for excluding PA [1]. More data on DRC, PAC and ARR in patients with and without PA under ongoing MR blocker treatment are, however, needed before using certain cut-offs of both, low DRC and low ARR, to exclude PA in such a setting in clinical routine. Nevertheless, this might improve future patient care because the possibility to exclude PA even under ongoing MR blocker treatment could prevent potentially harmful cessation of MR blockers for the purpose of PA diagnostics. It also bears mentioning that some reports suggest that in selected cases, subtype classification of PA (unilateral versus bilateral disease) by AVS may even be properly performed under ongoing MR blocker therapy, although we want to underline, that such an approach is currently not officially recommended for clinical routine [33]. Regarding subtype classification of PA it should also be mentioned that the diagnostic superiority of AVS versus computed tomography (CT) has been recently challenged, thus questioning the necessity of MR blocker discontinuation for differentiating unilateral versus bilateral disease in PA [34]. While this is still a matter of controversy, it should also be acknowledged that the recommended withdrawal time for MR blockers of 4 weeks before carrying out diagnostic evaluation for PA is based on rather limited evidence $[1,14]$. This issue warrants further studies including investigations to evaluate whether shorter withdrawal periods are also feasible. Apart from this, it is also tempting to speculate that the profound response to MR blockers in our GECOH patients with regard to DRC and the ARR might be of diagnostic value as an alternative confirmatory test for PA. While this hypothesis needs further evaluation, we want to stress that in our work all PA patients had a greater decline in the ARR when compared to any EPATH patient randomized to eplerenone. We consider this finding as hypothesis generating being aware of the limitations of our work with regard to assay comparability, sample size and patient selection. Nevertheless, we strongly recommend further investigations on this topic. Moreover, it should also be emphasized that MR blockers are, apart from PA therapy, also considered and recommended as an effective third or fourth line therapy in essential hypertension and are an established treatment for heart failure [35]. Considering this along with the fact that it has not been clearly established that surgery of aldosterone producing adenomas is superior with regard to hard clinical endpoints compared to MR blocker treatment, it may for some patients with indications for PA diagnostics, be justified to remain on their MR blocker treatment without further diagnostic evaluation for PA [1, 36-38].

As limitations of our work we have to acknowledge that participants from the EPATH study suffered from pHPT thus limiting the generalizability of our findings. Furthermore, due to the post-study analysis of the ARR in the EPATH trial, we did not perform additional confirmatory tests to exclude PA in participants with elevated $A R R$, and might thus have missed some undetected PA patients in that cohort. Other drawbacks of our work are the determinations of PAC and DRC in stored samples of the EPATH trial, and the low number of PA patients in the case series of the GECOH study [39]. Two patients in the GECOH study stopped beta-blocker intake after initiating MR blocker therapy and this clearly limits our findings because stopping beta-blockers significantly decreases the ARR. Furthermore, we did not study participants with aldosterone producing adenomas, in whom a particular strong aldosterone excess might be less sensitive to ARR changes by MR blocker treatment, and we used different assays in the two studies with therefore limited comparability. Main strengths are the validity of our PAC and DRC measurements as evidenced by the expected increase of these parameters after MR blocker treatment, and the fact that the data from the EPATH trial are the first to evaluate the effect of eplerenone on the ARR in a RCT. Furthermore, the previously reported excellent compliance and significant blood pressure reduction with eplerenone in the EPATH trial underscores the efficacy of this intervention [25].

In conclusion, we have observed that MR blocker treatment had no significant effect on the ARR in PHPT patients, whereas it significantly decreased the ARR in PA patients, an effect that was driven 
- Table 3 Characteristics of GECOH patients with primary aldosteronism at baseline and follow-up.

\begin{tabular}{|c|c|c|c|c|}
\hline Characteristics & Baseline & Follow-up & $\begin{array}{l}\text { Mean change from baseline } \\
\qquad(95 \% \mathrm{Cl})\end{array}$ & p-Value \\
\hline \multicolumn{5}{|l|}{ Patient 1} \\
\hline ARR (ng/dl/ $/ \mu \mathrm{U} / \mathrm{ml})$ & 8.37 & 2.11 & -6.26 & \multirow{3}{*}{ NA } \\
\hline PAC (ng/dl) & 25.1 & 33.9 & 8.8 & \\
\hline $\mathrm{DRC}(\mu \mathrm{U} / \mathrm{ml})$ & 3.0 & 16.1 & 13.1 & \\
\hline \multicolumn{5}{|l|}{ Patient 2} \\
\hline ARR (ng/dl/ $/ \mu \mathrm{U} / \mathrm{ml})$ & 13.87 & 1.94 & -11.93 & \multirow{3}{*}{ NA } \\
\hline PAC (ng/dl) & 22.2 & 42.0 & 19.8 & \\
\hline $\mathrm{DRC}(\mu \mathrm{U} / \mathrm{ml})$ & 1.6 & 21.6 & 20.0 & \\
\hline \multicolumn{5}{|l|}{ Patient 3} \\
\hline ARR (ng/dl/ $/ \mu \mathrm{U} / \mathrm{ml})$ & 7.95 & 2.54 & -5.41 & \multirow{3}{*}{ NA } \\
\hline PAC (ng/dl) & 30.2 & 67.4 & 37.2 & \\
\hline $\mathrm{DRC}(\mu \mathrm{U} / \mathrm{ml})$ & 3.8 & 26.5 & 22.7 & \\
\hline \multicolumn{5}{|l|}{ Patient 4} \\
\hline ARR (ng/dl/ $/ \mu \mathrm{U} / \mathrm{ml})$ & 14.76 & 4.20 & -10.56 & \multirow{3}{*}{ NA } \\
\hline PAC (ng/dl) & 36.9 & 64.7 & 27.8 & \\
\hline $\mathrm{DRC}(\mu \mathrm{U} / \mathrm{ml})$ & 2.5 & 15.4 & 12.9 & \\
\hline \multicolumn{5}{|l|}{ All patients $(n=4)$} \\
\hline ARR (ng/dl/ $/ \mu \mathrm{U} / \mathrm{ml})$ & $11.24 \pm 3.58$ & $2.70 \pm 1.03$ & $-8.54(-13.6$ to -3.5$)$ & 0.013 \\
\hline PAC (ng/dl) & $28.6 \pm 6.4$ & $52.0 \pm 16.6$ & 23.4 (4.2 to 42.6$)$ & 0.030 \\
\hline $\mathrm{DRC}(\mu \mathrm{U} / \mathrm{ml})$ & $2.7 \pm 0.9$ & $19.9 \pm 5.2$ & 17.2 (9.3 to 25.0$)$ & 0.006 \\
\hline
\end{tabular}

by a dramatic rise in DRC levels. Considering the relatively high prevalence of PA and the wide use of MR blockers we recommend further studies to evaluate (a) whether ARR response to MR blocker treatment may be useful as a diagnostic tool or even as a confirmatory test for PA, (b) evaluate whether certain cut-offs for both, low DRC and low ARR, can be established that allow exclusion of PA under ongoing MR blocker treatment, and (c) whether shorter withdrawal periods for MR blockers than the currently recommended 4 weeks are also accurate before performing PA diagnostics. Finally, we want to underline that our data are just hypothesis generating for future research but should not lead to any changes in clinical routine that deviate from current recommendations for the diagnostics of PA [1].

Clinical Trials Registration: EudraCT Number 2009-01812570 (additional registration at ClinicalTrials.gov Identifier NCT02136771).

\section{Acknowledgements}

The authors would like to thank the Laboratory of the Division of Endocrinology and Diabetology, Medical University of Graz, for its work and support to the present research. Samples and data used in this project were partly provided by the Biobank Graz of the Med- ical University of Graz, Austria. This study was supported by the Austrian National Bank (Jubilaeumsfond: project number 14621).

\section{Conflicts of Interest}

The authors declare that they have no conflict of interest.

\section{References}

[1] Funder JW, Carey RM, Mantero F, Murad MH, Reincke M, Shibata H, Stowasser M, Young WF Jr. The management of primary aldosteronism: Case detection, diagnosis, and treatment: An endocrine society clinical practice guideline. J Clin Endocrinol Metab 2016; 101: 1889-1916

[2] Stowasser M, Gordon RD. Primary Aldosteronism: Changing definitions and new concepts of physiology and pathophysiology both inside and outside the kidney. Physiol Rev 2016; 96: 1327-1384

[3] Milliez P, Girerd X, Plouin PF, Blacher J, Safar ME, Mourad J]. Evidence for an increased rate of cardiovascular events in patients with primary aldosteronism. J Am Coll Cardiol 2005; 45: 1243-1248

[4] Catena C, Colussi G, Nadalini E, Chiuch A, Baroselli S, Lapenna R, Sechi LA. Cardiovascular outcomes in patients with primary aldosteronism after treatment. Arch Intern Med 2008; 168: 80-85 
[5] Reincke M, Fischer E, Gerum S, Merkle K, Schulz S, Pallauf A, Quinkler M, Hanslik G, Lang K, Hahner S, Allolio B, Meisinger C, Holle R, Beuschlein F, Bidlingmaier M, Endres S.German conn's registry-else kröner-fresenius-hyperaldosteronism registry. Observational study mortality in treated primary aldosteronism: The German Conn's registry. Hypertension 2012; 60: 618-624

[6] Catena C, Colussi G, Brosolo G, Novello M, Sechi LA. Aldosterone and Left Ventricular Remodeling. Horm Metab Res 2015; 47: 981-986

[7] Tomaschitz A, Pilz S. Aldosterone to renin ratio-a reliable screening tool for primary aldosteronism? Horm Metab Res 2010; 42: 382-391

[8] Pilz S, Kienreich K, Gaksch M, Grübler M, Verheyen N, Bersuch LA, Schmid J, Drechsler C, Ritz E, Moosbrugger A, Stepan V, Pieber TR, Meinitzer A, März W, Tomaschitz A. Aldosterone to active Renin ratio as screening test for primary aldosteronism: Reproducibility and influence of orthostasis and salt loading. Horm Metab Res 2014; 46: 427-432

[9] Lichtenauer UD, Gerum S, Asbach E, Manolopoulou J, Fourkiotis V, Quinkler M, Bidlingmaier M, Reincke M. The Clinical Value of Salivary Aldosterone in Diagnosis and Follow-Up of Primary Aldosteronism. Horm Metab Res 2016; 48: 638-643

[10] Moors M, Williams TA, Deinum J, Eisenhofer G, Reincke M, Lenders JW. Steroid hormone production in patients with aldosterone producing adenomas. Horm Metab Res 2015; 47: 967-972

[11] Viola A, Monticone S, Burrello J, Buffolo F, Lucchiari M, Rabbia F, Williams TA, Veglio F, Mengozzi G, Mulatero P. Renin and aldosterone measurements in the management of arterial hypertension. Horm Metab Res 2015; 47: 418-426

[12] Mulatero P, Rabbia F, Milan A, Paglieri C, Morello F, Chiandussi L, Veglio $F$. Drug effects on aldosterone/plasma renin activity ratio in primary aldosteronism. Hypertension 2002; 40: 897-902

[13] Seiler L, Rump LC, Schulte-Mönting J, Slawik M, Borm K, Pavenstädt H, Beuschlein F, Reincke M. Diagnosis of primary aldosteronism: Value of different screening parameters and influence of antihypertensive medication. Eur J Endocrinol 2004; 150: 329-337

[14] Amar L, Lorthioir A, Azizi M, Plouin PF. Progress in primary aldosteronism. Mineralocorticoid antagonist treatment for aldosteroneproducing adenoma. Eur J Endocrinol 2015; 172: R125-R129

[15] Lowder SC, Liddle GW. Prolonged alteration of renin responsiveness after spironolactone therapy. A cause of false-negative testing for low-renin hypertension. N Engl J Med 1974; 291: 1243-1244

[16] Hammer F, Edwards NC, Hughes BA, Steeds RP, Ferro C], Townend JN, Stewart PM. The effect of spironolactone upon corticosteroid hormone metabolism in patients with early stage chronic kidney disease. Clin Endocrinol (Oxf) 2010; 73: 566-572

[17] Hood SJ, Taylor KP, Ashby MJ, Brown MJ. The spironolactone, amiloride, losartan, and thiazide (SALT) double-blind crossover trial in patients with low-renin hypertension and elevated aldosterone-renin ratio. Circulation 2007; 116: 268-275

[18] Seifarth C, Trenkel S, Schobel H, Hahn EG, Hensen J. Influence of antihypertensive medication on aldosterone and renin concentration in the differential diagnosis of essential hypertension and primary aldosteronism. Clin Endocrinol (Oxf) 2002; 57: 457-465

[19] Stowasser M, Ahmed AH, Pimenta E, Taylor P], Gordon RD. Factors affecting the aldosterone/renin ratio. Horm Metab Res 2012; 44: 170-176

[20] Sakamoto H, Ichikawa S, Sakamaki T, Nakamura T, Ono Z, Takayama Y, Murata K. Time-related changes in plasma adrenal steroids during treatment with spironolactone in primary aldosteronism. Am J Hypertens 1990; 3: 533-537

[21] Yagi A, Ichikawa S, Sakamaki T, Ono Z, Sato K, Nakamura T, Sakamoto H, Murata K. Aldosterone response to adrenocorticotrophin and furosemide in primary aldosteronism after prolonged spironolactone treatment. Eur J Endocrinol 1994; 131: 215-220
[22] Krum H, Nolly H, Workman D, He W, Roniker B, Krause S, Fakouhi K. Efficacy of eplerenone added to renin-angiotensin blockade in hypertensive patients. Hypertension 2002; 40: 117-123

[23] Rousseau MF, Gurné O, Duprez D, Van Mieghem W, Robert A, Ahn S, Galanti L, Ketelslegers JM.Belgian RALES Investigators. Beneficial neurohormonal profile of spironolactone in severe congestive heart failure: Results from the RALES neurohormonal substudy. J Am Coll Cardiol 2002; 40: 1596-1601

[24] Tomaschitz A, Fahrleitner-Pammer A, Pieske B, Verheyen N, Amrein K, Ritz E, Kienreich K, Horina JH, Schmidt A, Kraigher-Krainer E, Colantonio C, Meinitzer A, Pilz S. Effect of eplerenone on parathyroid hormone levels in patients with primary hyperparathyroidism: A randomized, double-blind, placebo-controlled trial. BMC Endocr Disord 2012; 12: 19

[25] Tomaschitz A, Verheyen N, Meinitzer A, Pieske B, Belyavskiy E, Brussee $\mathrm{H}$, Haas J, März W, Pieske-Kraigher E, Verheyen S, Ofner-Ziegenfuss L, Hartaigh BÓ, Schwetz V, Aberer F, Grübler M, Lang F, Alesutan I, VoelkI J, Gaksch M, Horina JH, Dimai HP, Rus-Machan J, Stiegler C, Ritz E, Fahrleitner-Pammer A, Pilz S. Effect of eplerenone on parathyroid hormone levels in patients with primary hyperparathyroidism: Results from the EPATH randomized, placebocontrolled trial. J Hypertens 2016; 34: 1347-1356

[26] Pilz S, Tomaschitz A, Stepan V, Obermayer-Pietsch B, FahrleitnerPammer A, Schweighofer N, Portugaller HR, Sourij H, Dobnig H, Meinitzer A, Pieber TR. Graz Endocrine Causes of Hypertension (GECOH) study: A diagnostic accuracy study of aldosterone to active renin ratio in screening for primary aldosteronism. BMC Endocr Disord 2009; 9: 11

[27] Pilz S, Kienreich K, Drechsler C, Ritz E, Fahrleitner-Pammer A, Gaksch M, Meinitzer A, März W, Pieber TR, Tomaschitz A. Hyperparathyroidism in patients with primary aldosteronism: Cross-sectional and interventional data from the GECOH study. J Clin Endocrinol Metab 2012; 97: E75-E79

[28] Moher D, Hopewell S, Schulz KF, Montori V, Gøtzsche PC, Devereaux PJ, Elbourne D, Egger M, Altman DG. CONSORT2010 explanation and elaboration: Updated guidelines for reporting parallel group randomised trials. BMJ 2010; 340: c869

[29] Tomaschitz A, Pilz S. Interplay between sodium and calcium regulatory hormones: A clinically relevant research field. Hypertension 2014; 63: 212-224

[30] Manolopoulou J, Fischer E, Dietz A, Diederich S, Holmes D, Junnila R, Grimminger P, Reincke M, Morganti A, Bidlingmaier M. Clinical validation for the aldosterone-to-renin ratio and aldosterone suppression testing using simultaneous fully automated chemiluminescence immunoassays. J Hypertens 2015; 33: 2500-2511

[31] O'Shea P, Brady J], Gallagher N, Dennedy MC, Fitzgibbon M. Establishment of reference intervals for aldosterone and renin in a Caucasian population using the newly developed Immunodiagnostic Systems specialty immunoassay automated system. Ann Clin Biochem 2016; 53: 390-398

[32] Vickers A], Altman DG. Statistics notes: Analysing controlled trials with baseline and follow up measurements. BMJ 2001; 323: 1123-1124

[33] Haase M, Riester A, Kröpil P, Hahner S, Degenhart C, Willenberg HS, Reincke M. Outcome of adrenal vein sampling performed during concurrent mineralocorticoid receptor antagonist therapy. J Clin Endocrinol Metab 2014; 99: 4397-4402

[34] Dekkers T, Prejbisz A, Kool LJ, Groenewoud HJ, Velema M, Spiering W, Kołodziejczyk-Kruk S, Arntz M, Kądziela J, Langenhuijsen JF, Kerstens MN, van den Meiracker AH, van den Born BJ, Sweep FC, Hermus AR, Januszewicz A, Ligthart-Naber AF, Makai P, van der Wilt G], Lenders JW, Deinum J. SPARTACUS Investigators. Adrenal vein sampling versus CT scan to determine treatment in primary aldosteronism: An outcome-based randomised diagnostic trial. Lancet Diabetes Endocrinol 2016; 4: 739-746 
[35] Dudenbostel T, Calhoun DA. Use of Aldosterone Antagonists for Treatment of Uncontrolled Resistant Hypertension. Am J Hypertens 2017; 30: 103-109

[36] Sechi LA, Colussi GL, Novello M, Uzzau A, Catena C. Mineralocorticoid receptor antagonists and clinical outcomes in primary aldosteronism: As good as surgery? Horm Metab Res 2015; 47: 1000-1006

[37] Vaidya A, Malchoff CD, Auchus RJ.AACE Adrenal Scientific Committee. An Individualized Approach to the Evaluation and Management of primary Aldosteronism. Endocr Pract 2017; 23: 680-689
[38] Willenberg HS. How to escape from primary aldosteronism? news and views on an adrenal disorder of salt retention. Horm Metab Res 2017; 49: $151-163$

[39] de Winter JCF. Using the Student's t-test with extremely small sample sizes. Pract Assess Res Eval 2013; 18: 1-12 